\title{
A Design of Swastika Shaped Wideband Microstrip Patch Antenna for GSM/WLAN Application
}

\author{
Vivek Singh Rathor ${ }^{1}$, Jai Prakash Saini ${ }^{2}$ \\ ${ }^{1}$ Mewar University, Chittorgarh, India; ${ }^{2}$ Department of EC, Bundelkhand Institute of Engineering and Technology, Jhansi, India. \\ Email: vivek_rathor@rediffmail.com,jps_uptu@rediffmail.com
}

Received November $25^{\text {th }}$, 2013; revised December $28^{\text {th }}$, 2013; accepted January $25^{\text {th }}, 2014$

Copyright (c) 2014 Vivek Singh Rathor, Jai Prakash Saini. This is an open access article distributed under the Creative Commons Attribution License, which permits unrestricted use, distribution, and reproduction in any medium, provided the original work is properly cited. In accordance of the Creative Commons Attribution License all Copyrights (C 2014 are reserved for SCIRP and the owner of the intellectual property Vivek Singh Rathor, Jai Prakash Saini. All Copyright (C) 2014 are guarded by law and by SCIRP as a guardian.

\section{ABSTRACT}

This paper presents a compact microstrip patch antenna at operating frequency of $2.5 \mathrm{GHz}$. The radiating element of the proposed antenna consists of Swastika symbol patch using dielectric substrate 4.2, loss tangent 0.0012 and having the same substrate height $1.6 \mathrm{~mm}$. The antenna size is very compact $(28.8 \mathrm{~mm} \times 37.2 \mathrm{~mm} \times 1.6$ $\mathrm{mm}$ ) and covers $1.696 \mathrm{GHz}$ to $2.646 \mathrm{GHz}$ and can be used for GSM and WLAN applications. Using IE3D software package of Zealand, the designed antenna is simulated. The computer simulation results show that the antenna can realize wideband characteristics having good impedance bandwidth of $43.758 \%$ (VSWR $\leq 2$ ) for all resonant frequencies. Our aim is to reduce the size of the antenna as well as increase the impedance bandwidth.

\section{KEYWORDS}

\section{Microstrip Antenna; Wide Band; Swastika Shape; IE3D}

\section{Introduction}

In recent years demand for small antennas on wireless communication has increased the interest of research work on compact microstrip antenna design among microwaves and wireless engineers. To support the high mobility necessity for a wireless telecommunication device, a small and light weight antenna is likely to be preferred. For this purpose compact microstrip antenna is one of the most suitable applications. The development of antenna for wireless communication also requires an antenna with more than one operating frequencies. This is due to many reasons, mainly because there are various wireless communication systems and many telecommunication operators using various frequencies [1]. However, the general microstrip patch antennas have some disadvantages such as narrow bandwidth etc. Enhancement of the performance to cover the demanding bandwidth is necessary [2]. Among these standards, the following frequency bands can be mentioned: 1) PCS-1900 requires a band of 1.85 - $1.99 \mathrm{GHz}$; 2) IEEE $802.11 \mathrm{~b} / \mathrm{g}$ requires a band of $2.4-2.484 \mathrm{GHz}$; 3) IEEE 802.11a requires a band of 5.15 - $5.35 \mathrm{GHz}$ and an additional band of 5.725 - $5.825 \mathrm{GHz}$; 4) HiperLAN2 requires a band of $5.47-5.725 \mathrm{GHz}$ besides the band of 5.15 - 5.35 GHz. Microstrip antennas are very attractive because of their low profile, low weight, conformal to the surface of objects and easy production. A large number of microstrip patches to be used in wireless applications have been developed; various shapes such as square, rectangle, ring, disc, triangle, elliptic, pentagonal [3]. There are numerous and well-known methods to increase the bandwidth of antennas, including increase of the substrate thickness, the use of a low dielectric substrate, the use of various impedance matching and feeding techniques, and the use of multiple resonators. So we want an antenna which offers a low profile, wide bandwidth, high gain and compact antenna element [2-22]. To overcome the above problem, a microstrip antenna structure with a typical Swastika symbol shaped slot is proposed which exhibits good impedance bandwidth of $43.758 \%$ which is suitable for GSM and WLAN (lower band application). Previously several papers have been published on the 
same shape but differ from this paper on design consideration, size, design parameters, operating frequency etc. Ram Singh [14] uses slotted patch, a compact triple band slot microstrip patch antenna for $1.7 / 2.92 \mathrm{GHz}$ WLAN applications. IE3D software is used for simulation work and slotted patch is used, which gives triple band. The radiating element of the proposed antenna consists of Swastika symbol slot operating at $1.8 \mathrm{GHz}, 2.09 \mathrm{GHz}$, and $2.92 \mathrm{GHz}$ bands, while Metamaterial Left-Handed Transmission Line model proposed by Vishav Gaurav Bhartiya [15] was presented. Authors analyze a Swastik design of metamaterial structure with a Rectangular Microstrip Patch Antenna and discussed and analyzed the performance of Patch Antenna with and without using the metamaterial structure. K. Jagadeesh Babu [16] proposed two element MIMO system resonates at a triband of $3.3 \mathrm{GHz}, 5.8 \mathrm{GHz}$, and $7.1 \mathrm{GHz}$ with an improved impedance bandwidth of $37 \%$. Modani, Uma Shankar [17] used HFSS and gave the stress on return loss. The proposed antenna has simulated return loss of $-29.5 \mathrm{~dB}$ at $5.8 \mathrm{GHz}$ frequency. The peak gain of this antenna at resonance frequency is $1.6 \mathrm{~dB}$. Vipul Jain [18] uses CST microwave studio and gives stress on characterization of "Swastik" shape and its effect on frequency domain parameter. Avinish Kumar Tripathi [19] proposed antenna on $1.8 \mathrm{GHz}$ (L-band) and $2.5 \mathrm{GHz}$ (S-band) frequentcy, which gives bandwidth of $18.3 \%$ \& $23.3 \%$ respectively.

\section{Antenna Design}

The dielectric constant of the substrate is closely related to the size and the bandwidth of the microstrip antenna. Low dielectric constant of the substrate produces larger bandwidth. The resonant frequency of microstrip antenna and the size of the radiation patch can be similar to the following formulas while the high dielectric constant of the substrate results in smaller size of antenna [1]. Figure 1 shows the geometry of the design in which the Length of ground plane of Antenna is $38.4 \mathrm{~mm}$ and Width is $46.8 \mathrm{~mm}$, L \& W of the patch is $28.8 \mathrm{~mm}$ \& $37.2 \mathrm{~mm}$.

The patch width, effective dielectric constant, the length extension and also patch length are given by

$$
W=\frac{c}{2 f \sqrt{\varepsilon_{r}}}
$$

where $c$ is the velocity of light, $\varepsilon_{r}$ is the dielectric constant of substrate, $f$ is the antenna working frequency, $\mathrm{W}$ is the patch non resonant width, and the effective dielectric constant is $\varepsilon_{\text {eff }}$ given as,

$$
\varepsilon_{\text {eff }}=\frac{\left(\varepsilon_{r}+1\right)}{2}+\frac{\left(\varepsilon_{r}-1\right)}{2}\left[1+10 \frac{H}{W}\right]^{-\frac{1}{2}}
$$

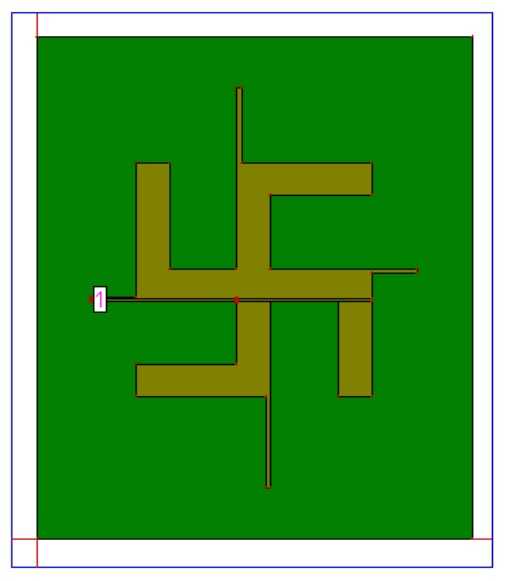

Figure 1. Top view of the microstrip patch antenna.

The extension length $\Delta$ is calculates as,

$$
\frac{\Delta L}{H}=0.412 \frac{\left(\varepsilon_{\text {eff }}+0.300\right)\left(\frac{W}{H}+0.262\right)}{\left(\varepsilon_{\text {eff }}-0.258\right)\left(\frac{W}{H}+0.813\right)}
$$

By using above equation we can find the value of actual length of the patch as,

$$
L=\frac{c}{2 f \sqrt{\varepsilon_{\text {eff }}}}-2 \Delta L
$$

\section{Simulated Results}

In this paper a compact wideband microstrip antenna with compact size is presented which gives a bandwidth of around $43.578 \%$. This bandwidth covers the frequency bands of GSM and WLAN (lower band) application. Figure 2 shows the return loss graph of microstrip antenna depicting the two resonant points at $1.8 \mathrm{GHz}$ and $2.49 \mathrm{GHz}$ and the simulated return loss is $-25.6 \mathrm{~dB}$ and $-22.64 \mathrm{~dB}$ respectively. Figure 3 shows the VSWR graph which is less than 2. Figure 4 shows the smith chart of the proposed design. Figure 5 shows the 3D radiation pattern of the proposed design. Figure 6 shows the Axial ratio graph which is near to zero and Figure 7 shows the Efficiency Vs Frequency curve which shows a high antenna efficiency of about $95 \%$ and radiating efficiency of about $95 \%$. Figure 8 shows the Gain Vs Frequency curve which shows maximum gain is achieved around $3 \mathrm{dBi}$ and Figure 9 shows the Maximum Directivity of $5 \mathrm{dBi}$.

\section{Conclusion}

In this paper a compact size microstrip antenna has been designed having good impedance matching as well as high antenna; efficiency of about $95 \%$ is achieved. The proposed antenna has larger impedance bandwidth of 


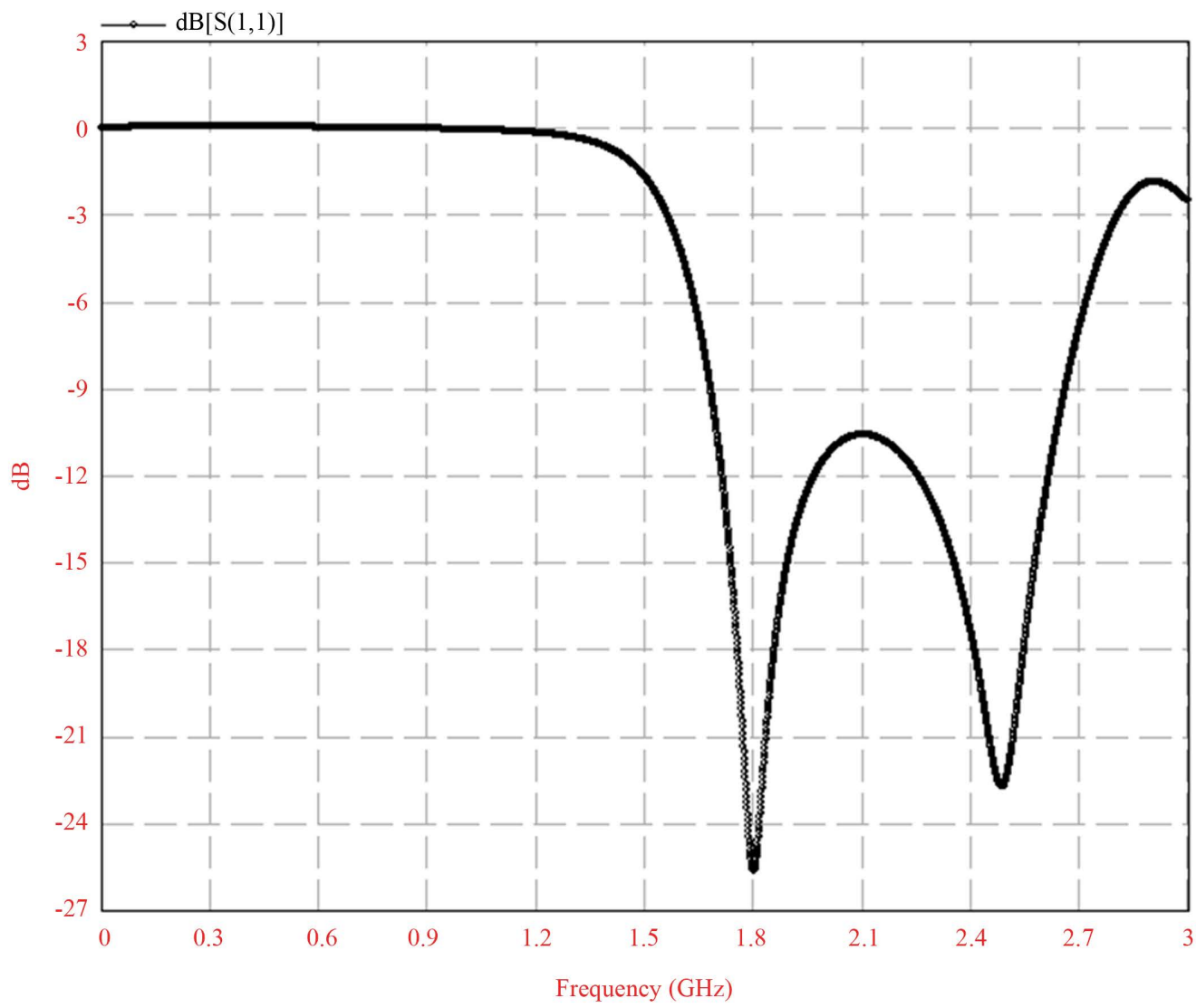

Figure 2. Return loss plot of the microstrip patch antenna.

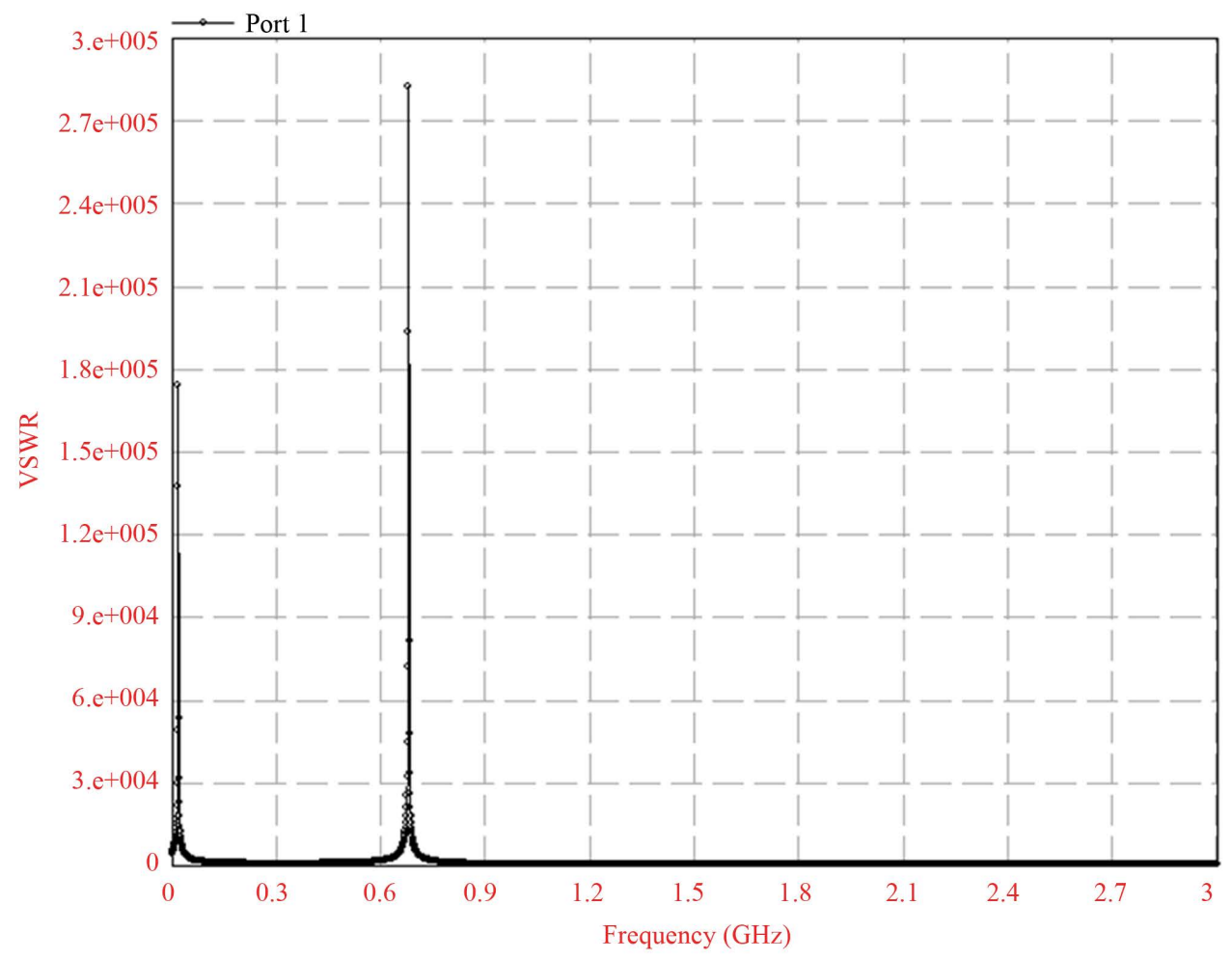

Figure 3. VSWR plot of the microstrip patch antenna. 
Impedamce in ohm

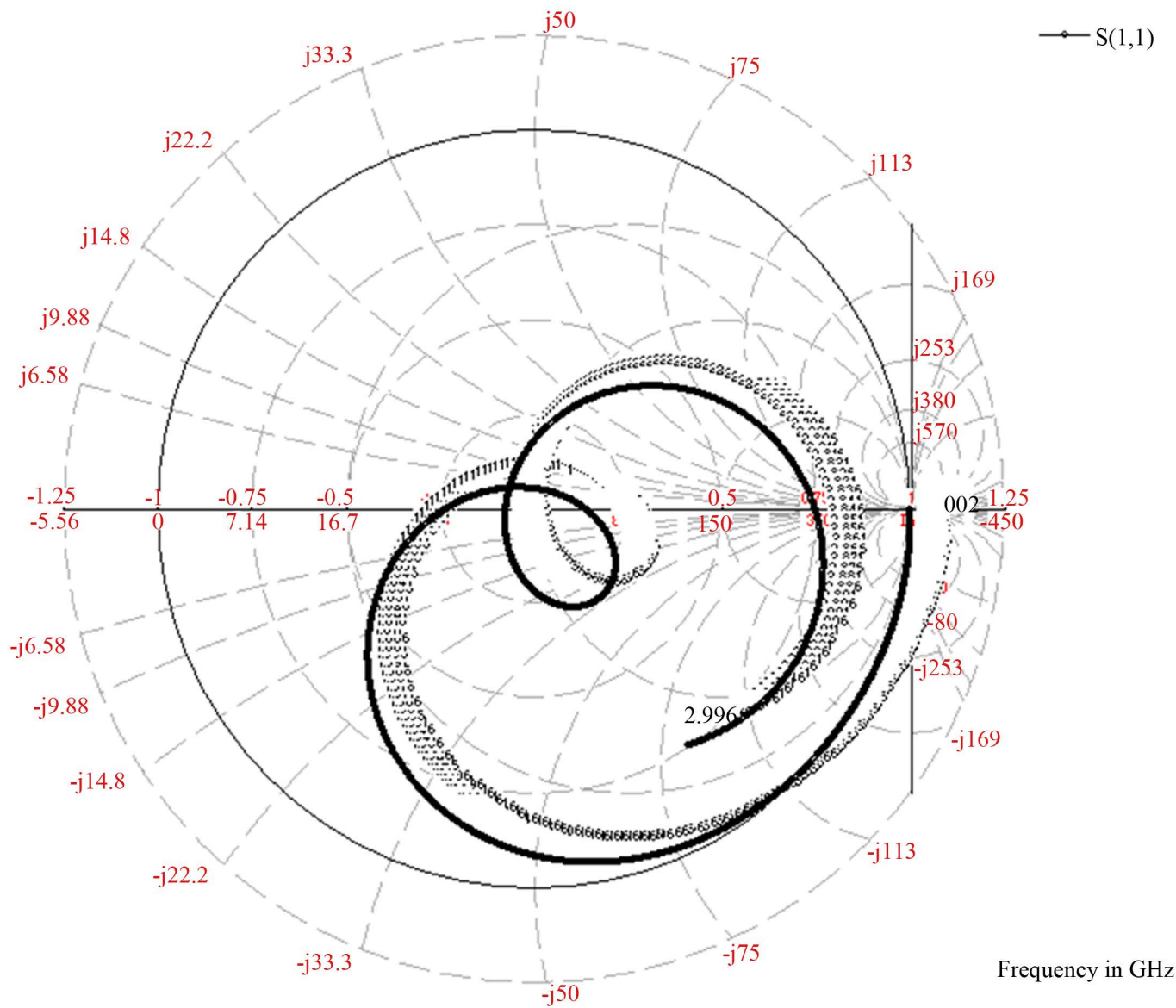

Figure 4. Smith chart of the microstrip patch antenna.

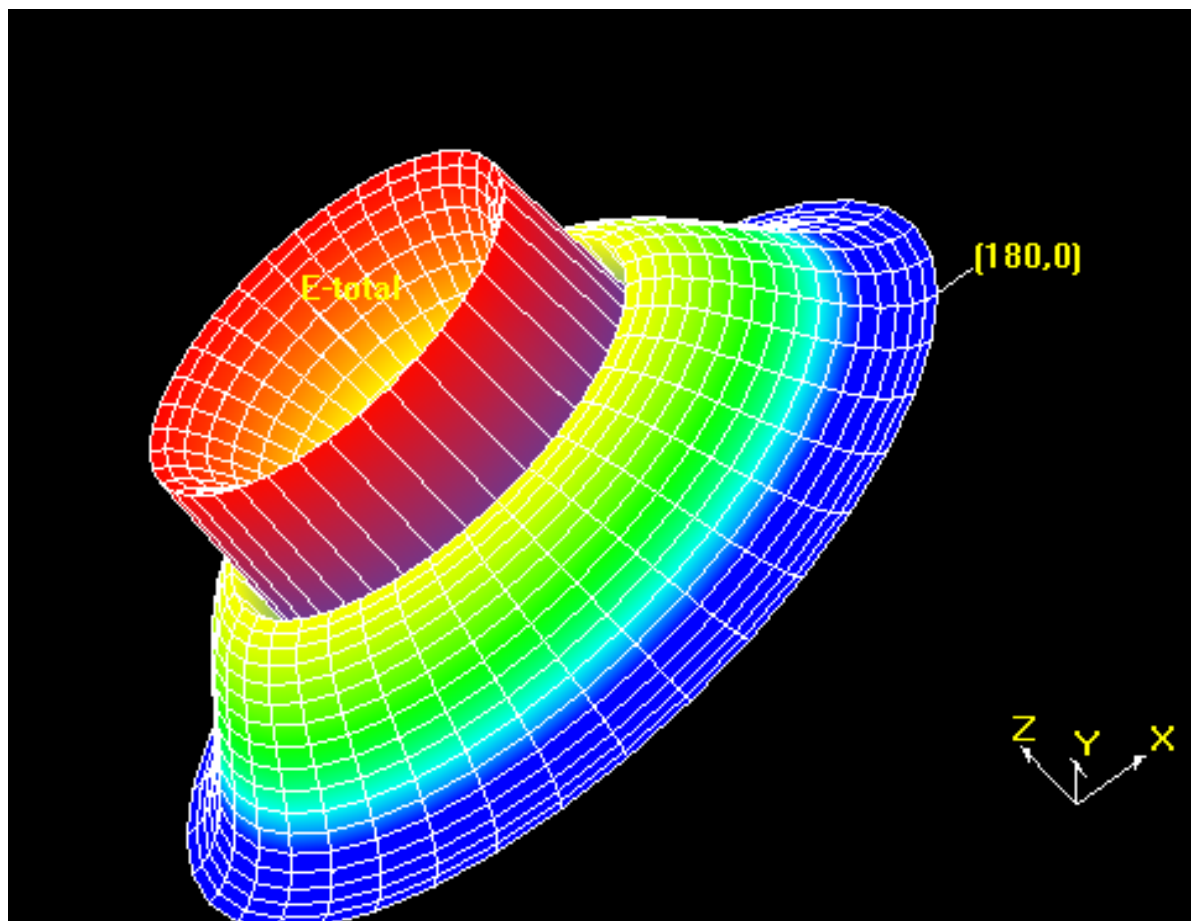

Figure 5. 3D Radiation pattern plot of the microstrip patch. 


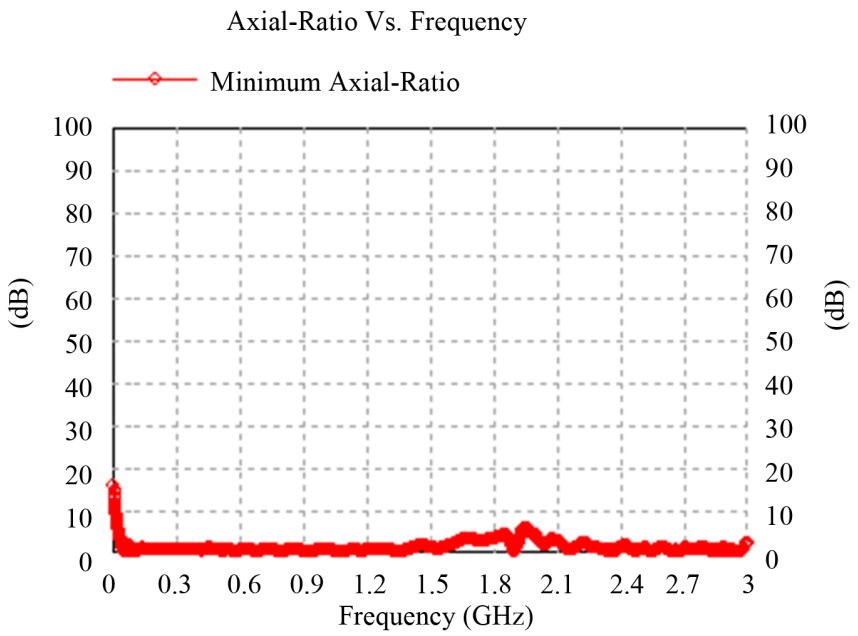

Figure 6. Axial ratio of the microstrip patch antenna.

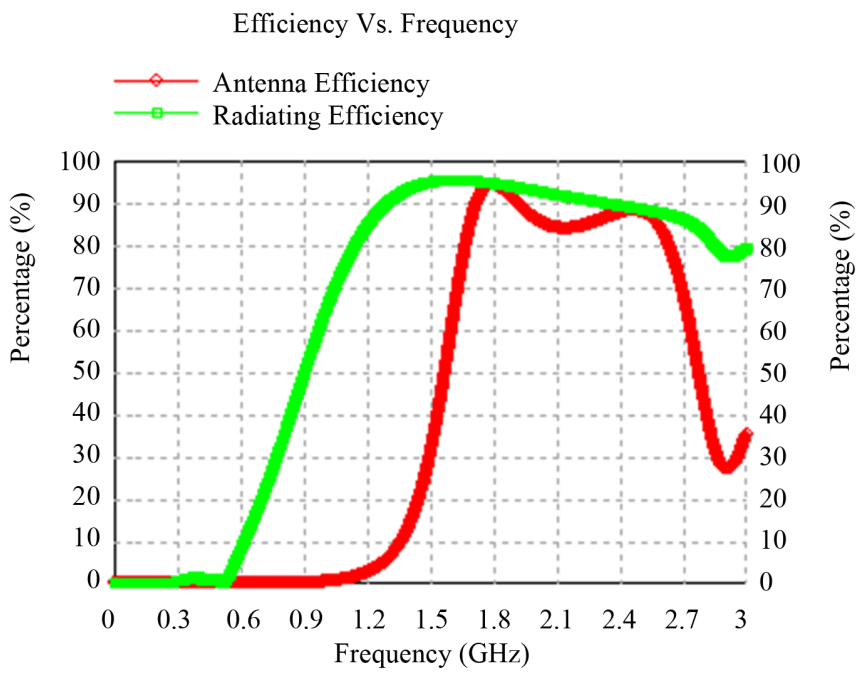

Figure 7. Efficiency plot of the microstrip patch antenna.

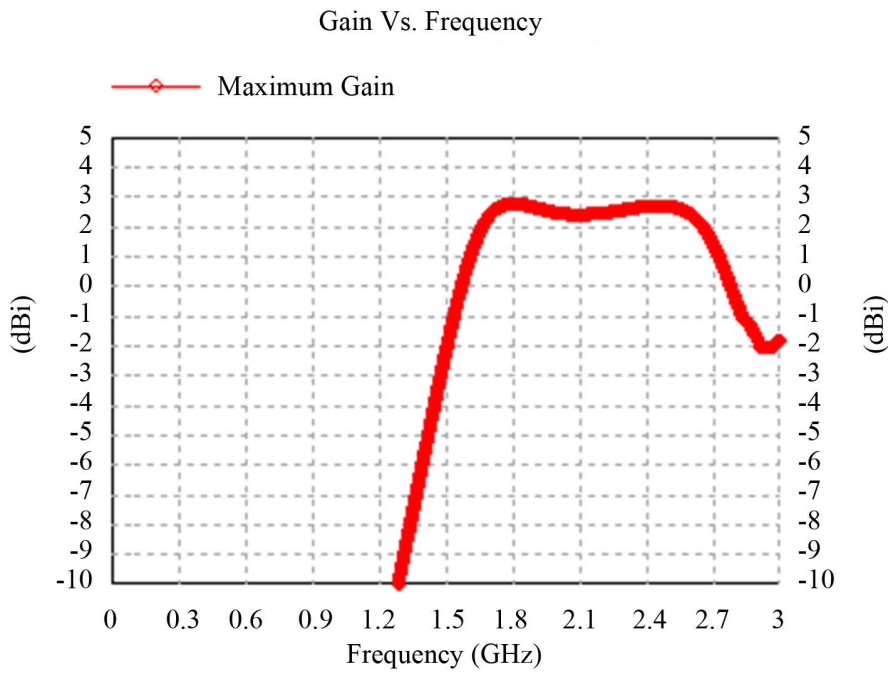

Figure 8. Maximum gain plot of microstrip patch antenna. 


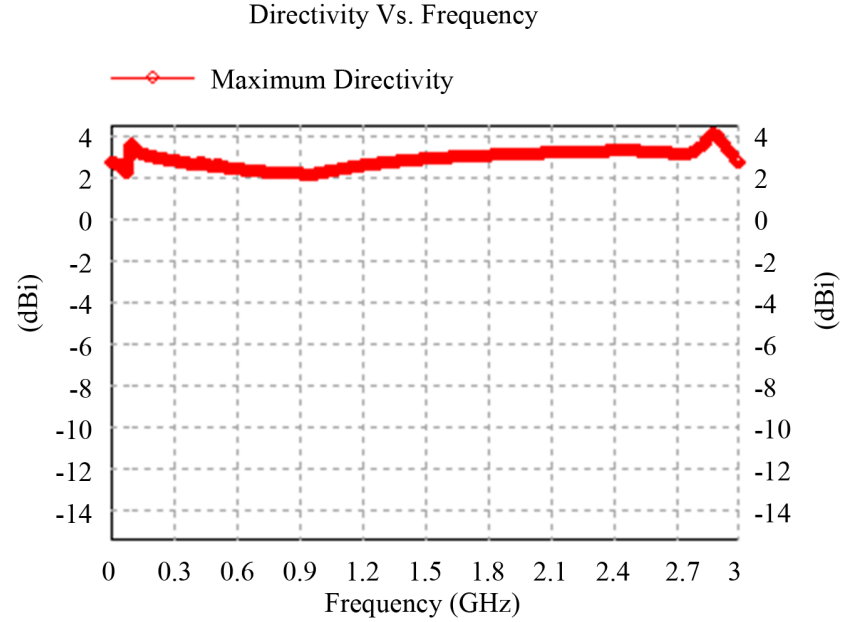

Figure 9. Directivity plot of microstrip patch antenna.

43.578\% covering the frequency range from $1.696 \mathrm{GHz}$ to $2.646 \mathrm{GHz}$ which is suitable for PCS-1900, GSM and WLAN (802.11b) applications.

\section{REFERENCES}

[1] X. F. Shi, Z. H. Wang, H. Su and Y. Zhao, "A H-Type Microstrip Slot Antenna in Ku-band Using LTCC Technology with Multiple Layer Substrates,” Second International Conference on Mechanic Automation and Control Engineering (MACE), Hohhot, 15-17 July 2011, pp. 7104-7106.

[2] U. Chakraborty, S. Chatterjee, S. K. Chowdhury and P. P. Sarkar, "A Compact Microstrip Patch Antenna for Wireless Communication,” Progress in Electromagnetics Research C, Vol. 18, 2011, pp. 211-220.

[3] H. Sabri and Z. Atlasbaf, "Two Novel Compact Triple Band Microstrip Annular-Ring Slot Antenna for PCS1900 and WLAN Applications,” Progress in Electromagnetics Research Letters, Vol. 5, 2008, pp. 87-98. http://dx.doi.org/10.2528/PIERL08110301

[4] A. Ramadan, K. Y. Kabalan, A. El-Hajj, S. Khoury and M. Al-Usseini, "A Reconfigurable U-Koch Microstrip Antenna for Wireless Applications," Progress in Electromagnetics Research, Vol. 93, 2009, pp. 355-367. http://dx.doi.org/10.2528/PIER09050605

[5] K. Qian and X. H. Tang, "Compact LTCC Dual-Band Circularly Polarized Perturbed Hexagonal Microstrip Antenna," IEEE Antennas and Wireless Propagation Letters, Vol. 10, 2011, pp. 1212-1215. http://dx.doi.org/10.1109/LAWP.2011.2173654

[6] K. Kumar and N. Gunasekaran, "A Novel Wideband Slotted mm Wave Microstrip Patch Antenna,” International Conference on Signal Processing, Communication, Computing and Networking Technologies (ICSCCN), Thuckafay, 21-22 July 2011, pp. 10-14.

[7] D. Xi, L. H. Wen, Y. Z. Yin, Z. Zhang and Y. N. Mo, “A Compact Dual Inverted C Shaped Slots Antenna for WLAN Application," Progress in Electromagnetics Research Letters, Vol. 17, 2010, pp. 115-123.

\section{http://dx.doi.org/10.2528/PIERL10073101}

[8] M. T. Islam, M. N. Shakib and N. Misran, "Broadband E-H Shaped Microstrip Patch Antenna for Wireless Systems," Progress in Electromagnetics Research, Vol. 98, 2009, pp. 163-173. http://dx.doi.org/10.2528/PIER09082302

[9] V. G. Kasabegoudar and K. J. Vinoy, "A Broadband Suspended Microstrip Antenna for Circular Polarization,” Progress in Electromagnetics Research, Vol. 90, 2009, pp. 353-368. http://dx.doi.org/10.2528/PIER09012901

[10] M. Alloyed, N. Kamjani and M. Shobeyri, “A Novel Cross-Slot Geometry to Improve Impedance Bandwidth of Microstrip Antennas," Progress in Electromagnetics Research Letters, Vol. 4, 2008, pp. 63-72. http://dx.doi.org/10.2528/PIERL08050203

[11] G. M. Zhang, J. S. Hong and B. Z. Wang, “Two Novel Band-Notched UWB Slot Antennas Fed by Microstrip Line,” Progress in Electromagnetics Research, Vol. 78, 2008, pp. 209-218. http://dx.doi.org/10.2528/PIER07091201

[12] A. Yu and X. X. Zhang, "A Method to Enhance the Bandwidth of Microstrip Antennas Using a Modified E-Shaped Patch," Proceedings of Radio and Wireless Conference, August 10-13, 2003, pp. 261-264.

[13] D. M. Pozar, "Microstrip Antennas," Proceedings of the IEEE, Vol. 80, No. 1, 1992, pp. 79-81. http://dx.doi.org/10.1109/5.119568

[14] R. S. Kushwaha, D. K. Srivastava and J. P. Saini, "Compact Triple Band Slotted Microstrip Patch Antenna,” International Journal of Engineering Science and Technology (IJEST), Vol. 4, No. 3, 2012, pp. 907-911.

[15] V. G. Bhartiya and L. Shrivastav, "Rectangular Microstrip Patch Antenna Using 'Array of Swastik' Shaped Metamaterial Structure,” Corona Journal of Science and Technology, Vol. 1, No. 1, 2012, pp. 11-14.

[16] K. Jagadeesh Babu, K. Sri Ramakrishna and L. Pratap Reddy, "A Triband Swastika Shaped Patch Antenna with Reduced Mutual Coupling for Wireless Mimo Systems," Journal of Electronics, Vol. 28, No. 4-6, 2011, pp. 
483-487.

[17] U. S. Modani and S. G. Modani, "Design of a Single Layer Swastik-Shaped Microstrip Patch Antenna,” International Journal of Operational Research \& Optimization, Vol. 2, No. 2, 2011, p. 455.

[18] V. Jain and J. K. Singh, "Effect of Swastik Shape Modified Ground Plane on Series Feed Micro Strip Patch Antenna with 2.6 GHz," International Journal of Research \& Technology, Vol. 1, No. 1, 2011, pp. 11-14.

[19] A. K. Tripathi, S. Srivastava and H. P. Sinha, "Design and Analysis of Swastik Shape Microstrip Patch Antenna at Glass Epoxy Substrate on L-Band and S-Band,” International Journal of Engineering and Innovative Technology (IJEIT), Vol. 2, No. 7, 2013, pp. 37-41.

[20] C. A. Balanis, “Antenna Theory,” John Wiley, 1982, pp 727-734.

[21] I. J. Bahl and P. Bharatia, “Microstrip Antennas,” Artech House, 1980.

[22] G. Kumar and K. P. Ray, "Broad Band Microstrip Antenna,” Artech House, 2003, pp. 1-21. 